\title{
Feria y verbena salmantina a \\ comienzos del s.XX. \\ una ventana a la \\ actividad artístico \\ musical a través de la \\ prensa local
}

Fair and verbena salmantina at the beginning of the XX Century.

A window to musical artistic activity through the local press

FRANCISCO JOSÉ Állarez GARCÍA

Universidad Pontificia de Salamanca 


\section{Historia}

$\Rightarrow$ Recibido 14/02/2019

Aceptado 01/04/2019

\section{Resumen}

El presente artículo extraído de un proceso de investigación más amplio, trata de recoger las principales características artístico-culturales de la feria, verbena y festejos populares salmantinos de comienzos del S.XX, sobre todo haciendo hincapié en la transformación que éstos sufrieron al final de la primera década. Los bailes populares y las celebraciones por barrios fueron, poco a poco, desapareciendo, dando lugar a otras modalidades de entretenimiento y disfrute. La principal fuente metodológica para extraer conclusiones, se apoya en la prensa local del momento, concretamente en el diario El Adelanto, periódico representativo de la época objeto de estudio.

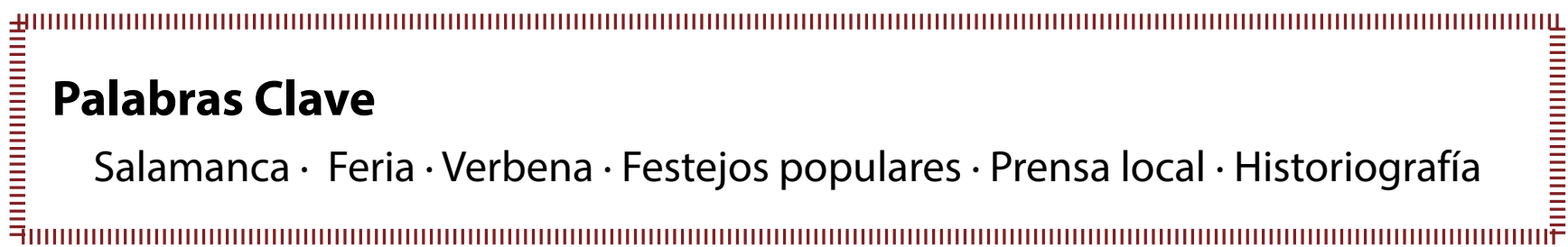

\section{Abstract}

The present article, extracted from a broader research process, tries to collect the main artistic-cultural characteristics of the feria, festivals and popular festivities of Salamanca in the early twentieth century, especially emphasizing the transformation that these suffered at the end of the first decade. The popular dances and the celebrations by neighborhoods were disappearing, giving rise to other modalities of entertainment and enjoyment. The main methodological source to draw conclusions, is supported by the local press at the time, specifically in the newspaper El Adelanto, the representative newspaper of the period under study..

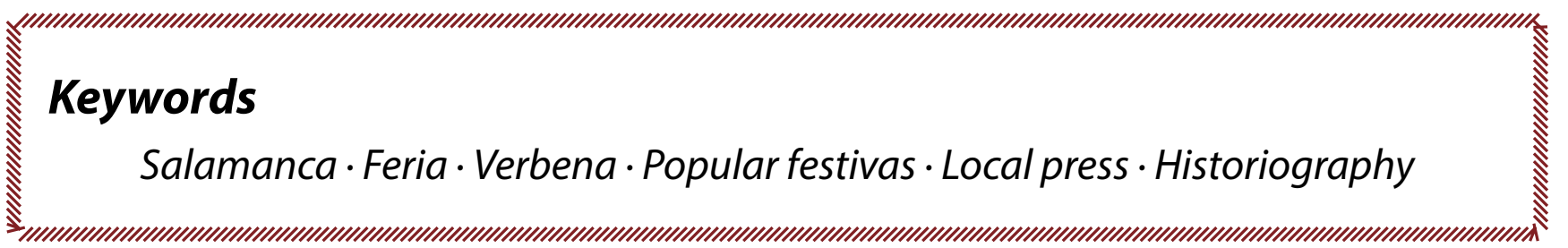




\section{Introducción: la prensa histórica como herramienta historiográgica}

Apoyarse en la prensa de una determinada localidad como fuente de datos y recurso principal en una investigación historiográfica, tiene ciertas ventajas y también algunos inconvenientes, que desde el comienzo hay que valorar, sopesar y saber encajar de la mejor manera posible (Palacios 2013). Desde luego las ventajas superan a los inconvenientes pues en los últimos años, son múltiples los estudios que utilizan este recurso como base de datos general.

Al igual que en nuestros días, un periódico local de comienzos del S.XX es un espejo bastante fiel de los acontecimientos, circunstancias y hechos más relevantes que, día a día, van salpicando el devenir cotidiano de sus protagonistas, los propios ciudadanos $y$, aunque ese espejo pueda estar ciertamente algo distorsionado por condicionamientos políticos de diferente índole, (al igual, de nuevo, que en la prensa y medios actuales), la realidad es que siempre han existido y existirán determinadas noticias de tipología neutra que, de alguna forma u otra, van a interesar prácticamente a todos los bandos y posiciones existentes. Por suerte, la música, así como la mayor parte de las disciplinas artísticas, está casi siempre dentro de este grupo.

De este modo, una participación de la banda municipal en la feria del libro de Salamanca en 2019, interesa a prácticamente todos los medios locales existentes, recogiéndose al día siguiente en los mismos, lo más relevante de la puesta en escena, obras interpretadas, número de asistentes, etc. Del mismo modo ocurría, por ejemplo, en 1906 con la celebración de una vistosa verbena o baile popular, la llegada de una nueva compañía de zarzuela, la creación de una banda o concierto de cualquier tipo de agrupación instrumental en un café de moda y en un sin fin de circunstancias musicales.

Así, hoy como antaño, lo que interesa es documentado y transmitido por los medios escritos (entre otros), a su vez, fiel reflejo de la propia sociedad protagonista y partícipe del evento. 
Por otra parte $y$, también a nuestro favor en la designación de la prensa local como fuente principal de recursos, la población de una capital de provincia como Salamanca era, a comienzos de siglo, mucho menor que la actual (correspondiéndose aproximadamente a su sexta parte). Si a este dato le sumamos las mucho más limitadas vías de ocio existentes en la época, en comparación con las actuales, obtenemos, para nuestro regocijo, (y siempre en proporción), muchas más noticias, reseñas, comentarios y artículos con la música como telón de fondo, altamente representativas de ese devenir cotidiano, cultural y social antes mencionado.

Dicho de otra forma: mientras que hoy en día, la sección dedicada al ocio de un diario local, ha de repartir su espacio entre infinidad de ofertas artístico culturales (desde conciertos, exposiciones, cine y teatro, hasta actividades relacionadas con las nuevas tecnologías, pasando, cómo no, por secciones deportivas, prácticamente inexistentes a comienzo de siglo), el mismo espacio, 100 años atrás, recoge muchas más actividades de ámbito musical que en la actualidad, al ser éste, con toda seguridad, el primer elemento cons- titutivo de entretenimiento local, junto con el teatro y el baile, (también con participación implícita en el género).

La periodicidad de El Adelanto (único diario de la capital salmantina a comienzos del S.XX), también es un punto fuerte a la hora de tratar festejos populares como la Feria y las verbenas ya que, normalmente, se detalla en cada ejemplar lo relevante del día o días circundantes a la propia publicación, obteniendo datos de cierta profundidad en ciclos temporales muy cortos, que pueden llegar a considerarse, incluso, como microhistoria, (tan relevante en recientes investigaciones historiográficas, al tratar contextos socio-artísticos).

Esta detallada profusión periodística, marca una importante diferencia por medio de la propia anécdota que, muchas veces, es capaz de decirnos mucho más sobre una determinada agrupación o circunstancia musical participante, de lo que podríamos obtener a través de un documento más amplio, en principio, pero no redactado en el entorno temporal de la verificación del acontecimiento, cuando el autor y los participantes del 
mismo, todavía saborean las mieles del, por ejemplo, concierto o baile recientemente disfrutado.

Así, gracias a la prensa, conocemos datos exactos de acontecimientos que en su momento fueron muy importantes pero que, poco a poco, fueron cayendo en el olvido (característica inherente a las circunstancias objeto de estudio del presente artículo).

Por contra, la utilización de la prensa, como fuente documental única o predominante, también tiene sus riesgos en cualquier trabajo de investigación de la tipología del presente.

Los periódicos son escritos por personas que, a su vez, viven, se expresan y redactan siguiendo, según qué casos, sus propias ideologías, que condicionan, en algunas informaciones, el propio contenido de las noticias. Así, en algunos casos, nunca sabremos con certeza si un redactor que critica a una determinada agrupación instrumental tras su actuación en un baile de feria, por ejemplo, realmente lo hace porque su intervención, interpretación, ejecución musical, etc., así lo mereció o si bien, por el contrario, inventó o exageró estos datos, para manifestar su descontento hacia las propias bailarinas que practicaban la "sicalipsis" (variante un tanto picante y de cargada connotación sexual en el género chico, sobre todo a comienzos del S. XX.)

En parte, este tipo de desajustes, se pueden atenuar cotejando, mismas noticias, en periódicos diferentes, siendo conscientes en todo momento de la ideología propia de cada uno de ellos. Incluso así, hemos de reconocer que, en algunos casos, la percepción de la realidad pudiera estar tan transformada por el propio redactor, que los datos obtenidos en la columna o artículo tuvieran que ser tomados, como se dice coloquialmente "con pinzas".

Sirvan como ejemplo, los siguientes fragmentos periodísticos tomados, el primero del periódico conservador, El Lábaro y el segundo, del popular y de tendencia algo más liberal, El Adelanto, en ambos casos refiriéndose entre otras cosas, a la interpretación de algunos cuplés, por parte de diferentes solistas, durante el programa lírico de la noche que ese día estaba formado por "Viento en Popa”, "Ruido de Campanas" y la controvertida "La Gatita Blanca", todas ellas zarzuelas en un acto. 
Como podemos observar, lo que para el primero es una interpretación "sucia y grosera", dentro de la parte objeto de controversia, para el segundo se trata de "una de las escenas culminantes de la noche".

\section{“(...) El Lábaro, que ha hecho siempre campaña manifiesta contra la inmoralidad no} podía menos de protestar como lo hace ahora con todas sus energías contra el espectáculo vergonzoso que anoche presenciamos en el Liceo (...) Uno de los couplets de "La Gatita blanca", cantado por la Querol, es tan fuerte y tan recargado...; hablando claro, es tan sucioy grosero, que nien una conversación íntima se atreverían muchos, muchísimos, a repetir, sin que en su rostro se notara el carmín del sonrojo y la vergüenza (...)’

“(...) el público tuvo aplausos para las escenas más culminantes de la zarzuela, especialmente en las que se cantan los couplets, que fue repetida ocho o diez veces, cantando los señores Montosa y Vidal otros tantos (...)" 2 .

Con todo esto en la mente del investigador, y sobre todo buscando, en los casos en los que sea posible, el punto de vista alternativo que pueda darnos un segundo o tercer periódico, la mayor parte de los conflictos "de percepción", se resuelven favorablemente, en el siguiente paso del trabajo: el análisis de los datos.

Pasemos, tras esta breve introducción a tratar las dos circunstancias populares con participación más importantes de Salamanca a comienzos del S.XX: su feria y verbenas populares.

\section{La feria salmantina a comienzos del s. XX}

La feria salmantina es sin duda, junto con el periodo de carnaval, la época más rica en manifestaciones artísticas populares (de todo tipo, pero sobre todo musicales) que encontramos en el ambiente musical salmantino charro, no sólo de la primera década,

1 “De espectáculos", El Lábaro-Salamanca-, 8 de Octubre de 1907; B.G.U.S.

2 "Teatro del Liceo", El Adelanto-Salamanca-, 8 de Octubre de 1907; B.G.U.S. 
sino de prácticamente todo el S. XX.

Las participaciones de bandas, orfeones, músicas y agrupaciones varias, zarzuela, etc., se multiplican en estos días festivos, concentrándose en pocos días, prácticamente un tercio del volumen global de la actividad musical anual.

El periodo festivo abarcaba siempre dos semanas, entre los días 8 y 21 de Septiembre, consignándose así toda la actividad en muy poco tiempo.

“(...) el día 8 de septiembre, como ya se sabe, comienza nuestra feria, y hasta su terminación, Salamanca vive una vida agitada; esto es, pierde su tranquilidad habitual. El día 21, San Mateo, le damos el cerrojazo y la capital recobra su vida corriente (...)" ${ }^{3}$.

Al tratarse de las fiestas locales por excelencia, su preparación, casi en su totalidad gestionada por el Ayuntamiento a través de la concejalía de Festejos, comenzaba varios meses antes de la llegada de las mismas, haciendo partícipes a los ciudadanos de las novedades y aconteci-

3 ANSEDE, C.R.: "El Carnaval se fue". De la Salamanca de ayer: usos, costumbres, recuerdos... Salamanca: Diputación de Salamanca, 1969. mientos más importantes previstos para las Ferias correspondientes.

El Municipio, cada año, intenta, con el reducido presupuesto del que dispone, corresponder los deseos de los salmantinos que, en la mayor parte de las ocasiones, aunque disfrutan de los festejos masivamente, no comparten los gustos con la Corporación Municipal, criticando, la mayor parte de los años las gestiones y actividades contratadas.

"Parece ser que la comisión de Festejos se preocupa de la formación de un programa de los que han de tener lugar en la próxima feria y que dentro del mezquino presupuesto de que dispone, trata de organizar algunos originales (...) 4 .

Tanto es así que, en referencia por ejemplo a la participación de las bandas musicales a través de la prensa, encontramos, prácticamente cada año, críticas a la contratación y gestión de los recursos municipales para la contratación de las mismas, manifestándose casi siempre de manera contraria a la forma de actuación del Ayuntamiento.

4 "Crónica Local y Provincial", El Adelanto -Salamanca-, 2 de Julio de 1900; B.G.U.S. 
En la siguiente reseña de El Adelanto, recojo, a modo de ejemplo, la propuesta y crítica realizada en un editorial contra la participación de bandas locales durante el periodo de ferias, y a favor de la contratación de una banda de prestigio, en este caso la recientemente constituida municipal de Madrid (que no llegó a actuar nunca en Salamanca, al menos durante la primera década del S.XX).

“(...) Es sabido en todos los actos y festejos es necesaria una banda de música que amenice a veces los intermedios, a veces los banquetes y espectáculos. Pues bien: en Salamanca no hay banda que pueda llenar cumplidamente y cómo debe exigirse a estos requisitos, dicho sea con perdón de la municipal, provincial y salesiana. $Y$ mucho menos, tratándose de la venida de los soberanos de España a Salamanca, con la que se hace precisa una banda buena. Así pues, yo propongo y brindó a los señores y entidades antes mencionadas, la idea de contratar para la feria a la banda municipal madrileña, recientemente formada, y que tan estruendoso éxito ha alcanzado en los conciertos celebrados. Los elementos de que está compuesta, son garantía suficiente para creer que su presencia aquí había de ser un ruidoso éxito. (...)" 5

Este tipo de retroalimentación y a la vez presión por parte de la ciudadanía a través de la prensa, surtía efecto de vez en cuando al tratar temas de importancia, como en la contratación de una determinada agrupación para el periodo de Feria.

Una vez terminado el periodo de "negociación", unos días antes del comienzo de los festejos, se anunciaba el programa, que siempre era publicado y puesto a la venta en la principales librerías de la ciudad. La mayor parte de las actividades y funciones presentadas, contenían participación musical, siendo los conciertos de una o dos bandas señaladas, la zarzuela de temporada y los desfiles y bailes tradicionales (populares y los celebrados en círculos y casinos), los eventos más esperados.

"Programa general de ferias y fiestas que se celebrarán en esta ciudad

en el próximo mes de Septiembre de 1900 (...) Día 8: Inauguración de la fe-

5 "Una idea", El Adelanto -Salamanca-, 14 de Junio de 1909; B.G.U.S. 
ria con disparo de voladores, toque de dianas y reparto de pan a los pobres de la ciudad. Tomará parte en la diana la banda de trompetas de la guarnición de caballería de esta plaza (...) El día 13 tendrá lugar en el Teatro del Liceo un concierto matinal por el laureado Orfeón Burgalés, por la tarde a las seis, segundo concierto en el paseo de la Alamedilla y por la noche, a las nueve, en la Plaza Mayor (...) Día 15: Las fuerzas de Caballería del Regimiento de Lanceros de Borbón y la Banda de Música del regimiento de infantería de Burgos organizarán una retreta y recorrerán las principales calles de la población (...) Durante los días 8 al 17 la Banda del Regimiento de Burgos amenizará los paseos y espectáculos públicos. Las tradicionales Gigantillas recorrerán las calles de la población y las músicas del país organizarán bailes públicos en las plazas y plazuelas de la ciudad. Los Casinos y Círculos de recreo obsequiarán a los forasteros con bailes de sociedad según costumbre. En el Teatro Bretón actuará una notable compañía de zarzuela de género chico. En el Liceo la que dirige el señor Bauzá en la que figuran los notables artistas señorita Fons y señores Simonetti y Munaín (...)" 6 .

En vez de abordar cada una de estas participaciones de modo cronológico, me limitaré a tratarlas y analizarlas en el presente artículo de manera genérica (al repetirse los patrones, prácticamente de año en año), centrándome así en el ambiente y el contexto que enmarcaban los propios eventos.

El periodo de ferias poseía (y sigue manteniendo) dos elementos pilares que hacían que la afluencia de gentes fuera masiva: las corridas de toros (único periodo taurino en la localidad) y el ferial de ganados, (situado en el teso de la feria, al otro lado del río)

Era precisamente, la tradicional "Mariseca" 7 , colocada en la espadaña de la Plaza Mayor el día de Santiago ( 25 de Julio), un mes y medio antes del comienzo de los festejos, la encargada de recordarnos el importantísimo tiempo taurino que se aproximaba. La celebración de este día, aunque lejos todavía de las populares fiestas, era ya considerado como parte de las mismas.

6 “Crónica Local y Provincial”, El Adelanto-Salamanca-, 18 de Agosto de 1900; B.G.U.S. 7 Estandarte con la silueta de un toro, anunciadora de las corridas de feria 


\section{“(..) La Mariseca en Salamanca, es} ya una institución y estoy seguro que el año en que, llegado el día de Santiago, no se tocase el reloj de la plaza, no se disparen cohetes, no tocase la música y no fuera elevada la pequeña bandera de la espadaña de la casa consistorial, habría terminado para muchos el encanto que para nuestra ciudad tiene el día de Santiago. (...). Lucen nuestras mujeres sus mejores y lujosas galas; puéblase la plaza de gentes de la ciudad y del campo, toca la música en el templete, $y$, durante un par de horas, bajo un sol espléndido y de fuego y bajo un cielo azul y hermoso, se respira ese ambiente de alegría y de regocijo, que sólo pueden dar el anuncio de unas corridas de toros magníficas, de las que todos estamos orgullosos, y a las que todos también deseamos éxito enorme (...)" 8 .

La participación de bandas o pequeñas secciones de las mismas en los eventos taurinos, era también una de las actividades musicales más características del periodo de feria.

8 "De la calle", El Adelanto -Salamanca-, 24 de Agosto de 1909; B.G.U.S.
"Según carta recibida por el presidente de la explotadora de la plaza de toros, vendrá para la próxima feria, con el fin de amenizar las corridas de los días 13 y 14, la banda de música portuguesa titulada "La Filarmónica", que tanta celebridad tiene alcanzada en todo el vecino reino, y premiada por S. M. el Rey (...)" 9 .

Ahora bien, aunque los festejos eran disfrutados por todos, el periodo de ferias estaba fundamentalmente dirigido al sector foráneo, buscando de este modo, la rentabilidad del pequeño negocio (que aprovechaba al máximo la estancia de las gentes de la provincia y de fuera) e intentando sacar el máximo partido a los pequeños y no tan pequeños consumos diarios (guardando fuerzas para temporadas no tan propicias). El ferial de ganados era, sin duda, la actividad comercial más importante.

“(...) Pero hemos de reconocer que la animación y la alegría que por todas partes se ve no la disfrutan todos, quiero decir que estas fiestas son principalmente para los forasteros y los desocupados, con respecto a las diversiones,

9 "Crónica Local y Provincial", El Adelanto -Salamanca-, 29 de Agosto de 1902; B.G.U.S. 
y lucrativamente para los dueños de cualquier negocio o comercio (....)" 10 .

Así, cualquier tipo de actividad musical (o festiva de cualquier tipo), buscaba la atracción del visitante, que dejaría, a través de su propio consumo, una aportación significativa, también a través de su participación en los propios festejos.

De esta manera, las compañías de zarzuela y género chico que no respondían a ningún tipo de patrón temporal para acudir a visitar la ciudad, durante la temporada de Feria se hacían siempre presentes, contratadas por los condominios del Liceo y Bretón, preocupados de tener los teatros con alguna compañía actuando (normalmente más importante que las del resto de la temporada).

Con la apertura del Teatro Moderno, a partir de 1909, la conocida como "Bombonera de don Cayo", se unió también a esta tradición.

"Dícese que en la próxima feria de septiembre actuará en el Teatro del Liceo una compañía de zarzuela seria y en el de Bretón una de género chico.

10 ANSEDE, C.R.: "El Carnaval se fue". De la Salamanca de ayer: usos, costumbres, recuerdos... Salamanca: Diputación de Salamanca, 1969.
Dichos dos coliseos han sido tomados en arrendamiento por una misma persona y no estarán abiertos a la par, más que en los días de las corridas" 11

Los bailes típicos en plazuelas públicas, también formaban parte de la tradición Ferial, consistiendo los mismos en bailes regionales, sobre todo castellanos, y más concretamente, de la propia provincia salmantina. Existían dos tipologías de espectáculo: los propiamente contratados por la municipalidad, que acudían normalmente de fuera de la provincia, y los enmarcados dentro del propio ambiente espontáneo y festivo, llevados a cabo por visitantes de la provincia y locales.

Los bailes en casinos y círculos de recreo también eran muy importantes durante el periodo de feria, estando abiertos circunstancialmente a visitantes foráneos (eso sí, presentados por un socio). Los bailes y conciertos se multiplicaban, realizándose multitud de contrataciones a músicos locales y de fuera en estas sociedades y cafés de todo tipo.

11 "Crónica Local y Provincial", El Adelanto-Salamanca-, 16 de Julio de 1900; B.G.U.S. 


\section{Verbenas y otros festejos locales a comienzos del s. XX}

Quizá la expresión tradicional por excelencia de las actividades festivas por barrios sea la verbena. Este tipo de celebraciones nocturnas se circunscriben en Salamanca, como prácticamente en toda España, dentro de la temporada de verano, y son siempre organizadas por barrios o parroquias siguiendo la tipología clásica, derivada sobre todo de la tradición castellana y madrileña.

De esta manera, el día 15 de Julio, festividad de la Virgen del Carmen, por ejemplo, es el propio barrio adscrito a la parroquia homónima la que prepara y organiza los festejos y ambientación de la verbena, en la que actúan como anfitriones ante los participantes de otros barrios.

\section{“(...) Los gastos son sufragados por} subscripción del vecindario (...)" 12.

La actividad musical en la verbena es lógicamente muy importante, al girar toda la celebración en torno a un baile popular ofrecido a los visitantes. Como veremos, dependiendo de la capacidad, solvencia y

12 “Crónica Local y Provincial", El Adelanto -Salamanca-, 15 de Julio de 1901; B.G.U.S. dedicación del barrio, esta música puede ir de la mano de una importante banda o pequeña orquesta, hasta ser humildemente interpretada por un manubrio de mano o pianola. También eran comunes las participaciones vocales e incluso de rondallas y tunas estudiantiles, aunque sólo de manera puntual, no como elemento constante a lo largo del festejo.

"En la plazuela de los Bandos tuvo lugar anoche la anunciada verbena, organizada con mucho gusto y a cuyo esplendor contribuyeron la banda de música del Hospicio y el Orfeón del Círculo de Obreros, que cantó varias obras con tanto arte como afinación"13.

En Salamanca la verbena experimentó, durante la primera década del S.XX, una evolución negativa en cuanto a su forma, fondo y participación, encontrando ejemplos de importante actividad en los primeros años para posteriormente, constatar poco a poco su desaparición por distintos motivos.

Así, las primeras reseñas de prensa, además de ser muy abundantes y corresponderse prácticamente con cada una de

13 “Crónica Local y Provincial”, El Adelanto-Salamanca-, 16 de Julio de 1902; B.G.U.S. 
las festividades representativas y objeto de verbena, son participadas y celebradas por toda la ciudad, no omitiendo gasto alguno el barrio o parroquia organizadores en atención al público visitante.

"Esta noche se inaugura en Salamancalatemporadadeverbenasconla que celebrarán en su barrio los vecinos de San Juan de Sahagún. Parece que se hacen grandes preparativos para que aquella resulte brillantísima"14.

"A juzgar por los preparativos que se hacen, promete ser brillante la verbena que ha de celebrarse hoy, como vispera de San Juan Bautista, en el barrio de este nombre. Todos los vecinos contribuyen con su óbolo a que el resultado sea brillante y digno de aquel populoso barrio, secundando la iniciativa de nuestro particular amigo don Manuel González Calzada" 15.

Las primeras participaciones musicales de la década, difieren bastante de las encontradas en el segundo y tercer tercio, acercándose más, en este primer tramo, a la tradición castellano-madrileña, con la polka, chotis y pasodoble típico como

14 “Crónica Local y Provincial", El Adelanto -Salamanca-, 11 de Junio de 1901; B.G.U.S.

15 "Crónica Local y Provincial", El Adelanto -Salamanca-, 23 de Junio de 1901; B.G.U.S. elemento distintivo, pasando, más adelante, a una transformación del programa adaptándose a la tradición bandística del momento, con fantasías románticas, aires de danza, adaptaciones de zarzuela, etc., por otra parte mucho menos bailables que el repertorio anterior.

Por otra parte, al ir adentrándonos en el segundo tercio de la década, observamos como, por diversas razones, la tradición se va diluyendo gradualmente, perdiéndose gran parte del boato y ceremonia participativa y de preparación por parte de los barrios $y$, como consecuencia, también reduciéndose el número de visitantes y su consiguiente actividad.

La parte musical, como es lógico, también fue perdiendo fuerza ya que, obviamente, su participación estaba ligada al contrato que cada barrio establecía con la banda, orquesta u agrupación pertinente $y$, al haberse recortado gastos, la música es la primera en resentirse.

La principal causa de estos recortes presupuestarios por parte del barrio o parroquia organizadora, tienen su origen en una medida polémica tomada por el Ayuntamiento en Junio de 1905, por la cual estableció una nueva tasa a cada co- 
rrespondiente comisión de vecinos, de 50 pesetas por baile y verbena que, como es lógico de suponer, contribuyó muy negativamente a la celebración de los tradicionales festejos, sobre todo en barrios más pequeños o menos populares.

De hecho, la mayor parte de las verbenas reseñadas por temporada más adelante, desaparecieron irremediablemente.

"Ya se pueden ustedes despedir de los bailes al aire libre" oí decir anoche a un mozalbete abonado desde hace tiempo a esta clase de espectáculos dirigiéndose a un corrillo de muchachas artesanas -¿Por qué?, le dijeron

-!Tó!... por "ná"... !Cualquiera puede satisfacer el recargo del Ayuntamiento!...

\section{¿¿Qué recargo?}

-Pues un recargo feroz, figúrense ustedes que el Ayuntamiento ha dicho "Vengan 50 pesetas y hay baile". De otro modo!"Piscis"!... Así es que ¿quién es el guapo que apunta esas 50 del ala para que otros se diviertan?

$Y$ ahora me explico fácilmente por qué no hubo baile ayernoche en la plazuela de San Juan de Barbalos y sí sólo una espléndida y elegante iluminación eléctrica. Los vecinos de aquel barrio han optado (y han hecho bien) por no dar ni baile ni las 50 pesetas (...)" ${ }^{16}$.

Incluso las verbenas más tradicionales y populares, correspondientes a los barrios más pudientes del centro de la ciudad, experimentan importantes recortes a causa de la impopular medida, que derivan en una falta de participación que, irremediablemente, acabará con la celebración de verbenas en la mayor parte de los barrios. También se acusa la pérdida de los valores tradicionales, base de la fiesta castellana, como el organillero, farolillos, buñuelos, chulos $y$, sobre todo, el propio baile, que, cada vez con menos frecuencia se celebra.

"Y digo que se celebraron, hablando en plural, suponiendo que pueda llamarse verbena al paseo-músico-luminoso anual que organizan siempre en dicho día los rumbosos vecinos de la Plazuela de los Bandos, donde está asentada la arcaica vivienda de doña María la Brava. Porque señores, aqueIlo no es Verbena... Es un rato de ocio que transcurre mientras el vecindario

16 "La Verbena de San Juan", El Adelanto -Salamanca-, 24 de Junio de 1905; B.G.U.S. 
se da unas vueltecitas por los jardiniIlos y escucha los trompetazos de una banda. Allí no hay organillo ni parejas que se marquen con todas las de la ley un schottis, ni chulos ni puestos de aguardiente, ni de bollos, ni de buñuelos, ni de alambres con farolillos, ni nada, en fin, quehuela averbena (...)"17.

Consciente de la pérdida paulatina de la bonita costumbre popular, el Ayuntamiento decide, a través de una nueva medida polémica, intentar reactivar la verbena tradicional, apoyándose en los propios fondos municipales vinculados a las Ferias de 1905. Para ello, organiza un concurso de verbenas por barrios, otorgando un premio de 500 pesetas al festejo mejor preparado y más animado. El resultado no pudo ser más desastroso los dos años en los cuales la medida se puso en práctica ${ }^{18}$

17 "Las Verbenas del Carmen”, El Adelanto -Salamanca-, 11 de Septiembre de 1906; B.G.U.S

18 Un siglo después y a partir de este divertido acontecimiento, se estrenó la zarzuela "Salamanca o la singular verbena del Paseo de la Estación", comedia lírica de costumbres salmantinas en dos actos y seis cuadros. Música y Libreto: Francisco José Álvarez García. Estreno: 9 de Junio de 2017. Teatro Liceo de Salamanca. Registro en la SGAE: 15782820
En Septiembre de 1905 unicamente participó una verbena organizada además, por un representante del propio Ayuntamiento, causa que originó el revuelo y la indignación entre la ciudadanía.

"El fracaso no puede haber sido mayor. Entiéndalo así el Ayuntamiento. El concurso de verbenas que anunció en sus flamantes programas de festejos para anoche ha quedado reducido a... la más mínima expresión. Tanto que sólo se ha registrado una verbena y para eso no muy vistosa, que digamos y organizada por apéndice, por un empleado del Municipio. !Claro, lo que él diría!, !No es cosa de dejar mal a mis señores!. $Y$ a todo trance hubo que hacer una verbena. Esta se celebró en el paseo de la Estación, frente al establecimiento de bebidas que dicho señor empleado, don Alfredo Fuentes, tiene instalado en aquel lugar (...)" 19 .

Y para las ferias de 1909, con un deterioro prácticamente total de la tradición, ni un solo barrio, parroquia o participación privada se presentó al concurso, quedando el mismo desierto.

19 "A través de los festejos", El Adelanto -Salamanca-, 17 de Julio de 1905; B.G.U.S. 
"(...) Para ayer, se anunciaba un concurso de verbenas, que quedó desierto por falta de eso, de verbenas (...)" 20 .

1906 y 1907, fueron reduciendo paulatinamente su actividad por barrios, encontrando, cada vez con más frecuencia, reseñas en prensa recordando y añorando tiempos mejores, cuando la verbena era uno de los festejos populares más significativos de la temporada de verano.

Al margen de los condicionantes económicos impuestos por el Ayuntamiento que, en principio, intentaban sufragar el gasto extra de luz que se realizaba durante la fiesta, es cierto también que, otra causa de la pérdida de interés por la tradición, tiene que ver con la propia organización del evento que, al intentar modernizarse y adaptarse a las nuevas costumbres, terminó por perder sus propias raíces, siendo rechazado por un importante sector de la población.

“(..) Los vecinos de este barrio que siempre se han distinguido por su esplendidez y buen humor, parece que de poco tiempo a esta parte se han modernizado de tal manera que ya

20 "La Feria", El Adelanto -Salamanca-, 15 de Septiembre de 1909; B.G.U.S. no nos sirven aquellas verbenas de tiempos atrás en las que habian farolillos, arcos, ramajes, puestos de churros, de vinos y de refrescos, sino que más "aristócratas" hoy cuelgan cuatro potentes focos de luz eléctrica en el centro de la plazuela, ordenan a "Cantarín" y demás "profesores" que comparezcan por el lugar del suceso $y$ nos endilgan unos cuantos chotises $y$ pasodobles y que más tarde la gente se encarga de invadir la calle y organizar en ella un animado paseo (...)" ${ }^{21}$.

El cambio de repertorio apuntado con anterioridad, también influyó negativamente en la consideración popular de las verbenas. En alguna ocasión, sobre todo ya en el último tercio de la primera década, verbenas tan importantes como la de Santiago, San Juan de Sahagún o la del Carmen, fueron suspendidas sin previo aviso. Las razones que aparecían reseñadas con más frecuencia eran de orden económico.

"Por la noche no se celebró la acostumbrada verbena en la Plaza de los Bandos. Este año, los ve-

21 "Vida Local", El Adelanto -Salamanca-, 24 de junio de 1907; B.G.U.S. 
cinos de dicho barrio se han "comprimido" y nos han suprimido, acaso por "mor" de la economía, el delicioso rato que en la popular verbena pasábamos los salmantinos" 22 .

"En la pintoresca plazuela de los Bandos, lugar ameno y delicioso, en el cual y en torno de los jardinillos de la fuente que envían aromas y frescor, se celebran las tradicionales verbenas de la virgen del Carmen, reinó anoche la más espantosa soledad. Ni un farolillo, ni un arco volcánico, ni una charanga, ni siquiera un modesto manubrio, fue llevado allí para solaz del vecindario que acudió presuroso, como en años anteriores, en los que hubo verbenas, a disfrutar de estas, llevándose el chasco consiguiente." ${ }^{23}$.

Las noticias en prensa cada vez eran más trágicas, consignando a la vez la pérdida irremediable de la tradición y la poca o ninguna participación de los salmantinos. Parece que desde todos los ámbitos, se hacían conscientes de la gravedad del asunto, llegando muchas veces a participar desde los propios editoriales de $E I$

22 "Noticias", El Adelanto-Salamanca-, 16 de Julio de 1907; B.G.U.S.

23 "Se acabaron las verbenas", El Adelanto -Salamanca-, 16 de Julio de 1908; B.G.U.S.
Adelanto, en vez de desde los tradicionales apartados de "Noticias".

“(...) Y lo que, anoche se conmemoró en tiempos pasados con verbenas espléndidas llenas de luz, de mujeres bonitas y rebosantes de alegría, hoy se rememora tristemente, con los chillones ecos de un manubrio, con la calle casi a oscuras y con contadas personas serias y graves, taciturnas y displicentes. Acaso mañana muera por completo la tradición y no nos quede de ello ni el recuerdo. Que después de todo, es esto preferible a los funerales cumplidos y solemnes que hoy se hacen y que por aquí se empeñan en llamar verbenas... verbenas donde goza el pueblo. ¿Qué pueblo? ¿el alegre?. Y ¿cómo va a haber pueblo alegre si este pueblo no tiene dinero?. He ahí la muerte de las verbenas." 24.

En todo 1910, sólo aparece recogida en prensa una noticia referente a una verbena de organización privada, con la banda "El $1^{\circ}$ de Mayo" como entidad organizadora. La tradición decimonónica, quedaba definitivamente clausurada a comienzos de la segunda década del S. XX.

24 "La víspera de San Juan", El Adelanto -Salamanca-, 12 de Junio de 1909; B.G.U.S. 
Paso a reseñar cronológicamente las distintas verbenas y fiestas populares que, como ya hemos visto, sobre todo en el primer tercio de siglo, iluminaban las noches estivales salmantinas.

\section{Distribución de las verbenas y bailes populares a comienzos del s. XX}

La primera verbena en el calendario, aunque de tradición tardía, es la celebrada por la Federación Obrera con motivo de la víspera del día del trabajo. El Orfeón Obrero, vinculado a la misma, participaba cada año. Estas verbenas se celebraban en la calle donde la sociedad poseía su local, en el Arco de la Lapa y eran participadas, sobre todo, por artesanos, obreros y trabajadores de diferentes gremios e industrias.

“(...) En la noche del día 30 de abril, víspera de la fiesta, se celebrará una verbena en la calle donde está instalado el Centro Obrero (Arco de la Lapa), con vistosas iluminaciones, cantando el orfeón obrero a las doce de la misma, para saludar al nuevo día (...)"25.

A finales de mayo, encontramos algunos años verbenas de tipología esporádica, dedicadas a la Virgen, en el mes tradicionalmente dedicado por la Iglesia, a la madre de Jesús. Aquí tenemos una, reseñada por El Adelanto, en el Arrabal del Puente.

"Anoche se celebró una verbena en el Arrabal del Puente en honor de la Virgen, resultando muy concurrida y animada (...)" ${ }^{26}$.

En junio, la verbena de San Antonio, celebrada en el frontón de San Bernardo, era el anticipo de las más populares, que llegarían con las noches más calurosas.

"El miércoles próximo, festividad de San Antonio, se celebrará una elegante verbena en el frontón de San Bernardo, en cuyo espacioso sitio tendrálugar un baile de confian-

25 "Vida Obrera", El Adelanto-Salamanca-, 29 de Abril de 1905; B.G.U.S.

26 "Crónica Local y Provincial", El Adelanto-Salamanca-, 22 de Mayo de 1904; B.G.U.S. 
za y por invitación, que durará hasta las dos y media de la madrugada" ${ }^{27}$.

San Juan Bautista, a mediados del mismo mes, aunque no se celebraba todos los años, gozaba de una gran participación a comienzos de siglo.

\section{“(...) A juzgar por los preparativos} que se hacen, promete ser brillante la verbena que ha de celebrarse hoy como víspera de San Juan Bautista, en el barrio de este nombre. Todos los vecinos contribuyen con su óbolo a que el resultado sea brillante y digno de aquel populoso barrio, secundando la iniciativa de nuestro particular amigo don Manuel González Calzada (...)" 28 .

Con el solsticio de verano, fecha por excelencia tradicional de la verbena estival, se celebraban las de San Juan de Barbalos y San Juan de Sahagún, que, normalmente, se simultaneaban en el calendario. Junto con la del Carmen y Santiago, estas eran las verbenas más participadas por el pueblo

27 "Crónica Local y Provincial", El Adelanto -Salamanca-, 11 de junio de 1900; B.G.U.S.

28 "Crónica Local y Provincial", El Adelanto -Salamanca-, 23 de Junio de 1901; B.G.U.S.
“(...) Muchas fueron las celebradas anoche para conmemorar la festividad de San Juan y la animación fue grandísima hasta las primeras horas de la mañana. Entre todas descollaba por la riqueza y buen gusto de la iluminación, la de San Juan de Barbalos en cuya plazuela era punto menos que imposible el tránsito. Dificilillo es que en Salamanca haya algún otro barrio con humor suficiente para quitarle la palma al de San Juan, en lo que a verbenas se refiere" ${ }^{29}$.

Muchas veces, la noche de San Juan transcendía a otras parroquias y localizaciones, convirtiéndose en una fiesta prácticamente de cada barrio salmantino.

“(...) En otros puntos como el Corrillo y calle de Caleros, también hubo verbenas muy animadas" 30.

La víspera de la festividad de San Pedro, el 28 de junio, se celebraban, también con carácter prácticamente general, las tradicionales verbenas con sus correspondientes hogueras.

29 "Crónica Local y Provincial", El Adelanto -Salamanca-, 24 de junio de 1900; B.G.U.S.

30 "Crónica Local y Provincial", El Adelanto-Salamanca-, 24 de Junio de 1901; B.G.U.S. 
"La verbena de San Pedro celebróse anoche en Salamanca con gran animación, siendo muchos los bailes y hogueras en las calles (...)" ${ }^{31}$.

Ya en julio, la Festividad de la Virgen del Carmen, el día 15, era sin duda el festejo más esperado. La participación musical en la Plaza de los Bandos, lugar común de celebración, era siempre la más rica, contratando con frecuencia a la banda más importante que durante la temporada registrara actividad.

"La verbena celebrada anoche en la Plaza de los Bandos con motivo de la festividad de la Virgen del Carmen, superó acaso las esperanzas de los vecinos, que realizaron tan hermosa fiesta. Cuatro grandes focos eléctricos y numerosas lámparas esparcían por todas partes una gran claridad. Sin embargo hay que reconocer que, para una verbena del género clásico, faltaban allí los farolillos de colores, los buñuelos y los pianos de manubrio. Yademás las parejas marcándose en Polkas y schotis. La plaza estuvo llena por completo de espectadores hasta las doce de la noche. La banda del Protectorado ejecutó las más escogidas piezas de su repertorio y el Orfeón del Círculo Obrero, cantando con sumo gusto, demostró que con el tiempo podrá figurar entre los mejores" ${ }^{\prime 2}$.

Gracias a El Adelanto recojo a continuación un ejemplo de lo que podía ser la participación clásica en una verbena de comienzos de siglo. Cuando, como en este caso, era una banda la encargada de amenizar el baile, el repertorio se alejaba bastante del programa tradicional castellano, dejando los chotis, polkas y la mayor parte de los pasodobles al piano de manubrio.

"He aquí las piezas que prepara la banda de la Casa de Beneficencia para la velada que se celebrará el día 15 de los corrientes, en la plazuela de los Bandos a las nueve de la noche, con motivo de la festividad del Carmen. 1a Pasodo-

31 "Crónica Local y Provincial", El Adelanto-Salamanca-, 29 de Junio de 1901; B.G.U.S.

32 "Crónica Local y Provincial", El Adelanto-Salamanca-, 16 de Julio de 1901; B.G.U.S. 
ble. $2^{a}$ Una serenata (sinfonía). 3a Coro y brindis, de la zarzuela "Robinsón". 4a "A orillas del Turia". Vals. 5a Sinfonía sobre "Aires montañeses". 6a "Tarjeta postal", mazurca. 7a "Elgueta", redoble militar. 8a Sinfonía sobre aires de zarzuela" ${ }^{33}$.

Coincidiendo con la colocación de la tradicional "Mariseca" anunciando las corridas de feria, la parroquia y barrio de Santiago organizaba la víspera su verbena, que era también tradicionalmente muy participada. Ésta era la última de la temporada, al margen de las celebradas por ferias, organizadas por la Corporación Municipal.

"Anoche se celebró un animado baile en la inmediaciones de la iglesia de Santiago en el cual no ocurrió incidente alguno desagradable. Esta noche habrá otra vez baile" ${ }^{34}$.

En alguna ocasión, con motivo del fin de feria, se celebró verbena o bailes públicos en honor de San Mateo, el 21 de Septiembre, aunque no de manera tradicional.

"Anoche, con motivo de la festividad de San Mateo, celebráronse bailes públicos de gaita y dulzaina en la Plaza de la Verdura y del Corrillo, siendo extraordinarios la animación y el orden que reinaron hasta su terminación" ${ }^{35}$.

33 "Salamanca", El Lábaro -Salamanca-, 12 de Julio de 1902; B.G.U.S.

34 “Crónica Local y Provincial", El Adelanto -Salamanca-, 25 de Julio de 1904; B.G.U.S.

35 “Crónica Local y Provincial”, El Adelanto-Salamanca-, 22 de Septiembre de 1904; B.G.U.S. 


\section{Referencias Bibliográficas}

Ansede, C.R. (1969). El Carnaval se fue. De la Salamanca de ayer: usos, costumbres, recuerdos...: Diputación de Salamanca, 1969.

Álvarez García, Francisco J. (2009). La actividad musical en Salamanca a través de la prensa local 1900-1910. Salamanca: Ediciones Universidad de Salamanca.

Álvarez García, Francisco J. (2012). Músicos en Salamanca a comienzos del siglo XX. Salamanca: Universidad Pontificia de Salamanca.

Álvarez García, Francisco J. (2013). Compañías de zarzuela y teatro lírico en Salamanca a comienzos del siglo XX. Salamanca: Universidad Pontificia de Salamanca.

Álvarez García, Francisco J. (2018). Salamanca o la singular verbena del paseo de la estación. Una zarzuela del $\mathrm{s}$. XXI como ventana a la actividad musical salmantina de comienzos del s. XX. Artseduca, (20), 78-96.

López, Zósimo; Nunes, Pedro y Val, Fernán. (2017). Una introducción a los estudios sobre periodismo musical. Madrid: Cuadernos de Etnomusicología, №10.

Muñoz Tuñón, A. (2000). Gálvez. En Casares Rodicio, E. (dir.), Diccionario de la música española e hispanoamericana (vol. 5, p. 358). Madrid: SGAE.

Palacios, María (2013). Prensa e historia. Universidad de Salamanca: Revista de musicología, vol XXXVI, n 1-2 (2013). Reseñas bibliográficas (pp. 336-339). ISSN 0210-1459

Periódico El Adelanto -Salamanca-, Biblioteca General de la Universidad de Salamanca.

Periódico El Lábaro -Salamanca-, Biblioteca General de la Universidad de Salamanca. 